Article

\title{
Potentiometric Signal Transduction for Selective Determination of 1-(3-Chlorophenyl)piperazine "Legal Ecstasy" Through Biomimetic Interaction Mechanism
}

\author{
Eman H. El-Naby
}

Narcotic Department, National Center for Social and Criminal Research, P.O. Zamalek Post, Cairo 11561, Egypt; emanhasab@gmail.com

Received: 2 July 2019; Accepted: 7 September 2019; Published: 16 September 2019

check for updates

\begin{abstract}
CPP})$ is a wide spread new psychoactive substance produces stimulant and hallucinogenic effects similar to those sought from ecstasy. Hence, in the recent years, $\mathrm{mCPP}$ has been introduced by the organized crime through the darknet as a part of the illicit ecstasy market with a variable complex profile of pharmacologically active substances that pose problematic risk patterns among people who take these seized products. Accordingly, the design of selective sensors for the determination of $\mathrm{mCPP}$ is a very important demand. In this respect, a supramolecular architecture; [ $\mathrm{Na}(15-\mathrm{crown}-5)]\left[\mathrm{BPh}_{4}\right]$ from the assembly of 15 -crown- 5 and sodium tetraphenylboron has been utilized as an ionophore, for the first time in the selective recognition of mCPP in conjunction with potassium tetrakis(p-chlorophenyl)borate and dioctylphthalate through polymeric membrane ion sensors. The ionophore exhibited a strong binding affinity that resulted in a high sensitivity with a slope closed to the ideal Nernstian value; $58.9 \pm 0.43 \mathrm{mV} /$ decade, a larger dynamic range from $10^{-6}$ to $10^{-2} \mathrm{M}$, a lower limit of detection down to $5.0 \times 10^{-7} \mathrm{M}$ and a fast response time of $5 \mathrm{~s}$. Very important also is it was afforded excellent selectivity towards mCPP over psychoactive substances of major concern, providing a potentially useful system for the determination of $\mathrm{mCPP}$ in the illicit market. On comparison with the natural $\beta$-cyclodextrin as an ionophore, it exhibited more sensitivity and selectivity estimated to be the superior.
\end{abstract}

Keywords: 1-(3-chlorophenyl)piperazine; mCPP; legal ecstasy; new psychoactive substances; ion selective sensors; supramolecular based sensors; molecular recognition; 15-crown-5; sodium tetraphenylboron; potentiometric sensors

\section{Introduction}

The abuse of illicit drugs that can threaten all aspects of life; social, public health, economy, wellbeing and so on has been and continues to be the subject of much importance all over the world. Alarmingly, in recent years the situation has become more and more complicated; a huge variety of synthetic psychoactive substances has been surfacing in the illicit drug market alternative to the illegal ones. They mimic the pharmacological effects of the existing controlled drugs and deliberately circumvent regulations. These substances are called new psychoactive substances and referred as "NPS", "designer drugs", "legal high" or "research chemicals". The totally synthetic piperazine-based compounds; 1-benzylpiperazine (BZP), 1-(3-chlorophenyl)piperazine or m-chlorophenylpiperazine (mCPP); Figure 1, 1-(3-trifluoromethylphenyl)piperazine (TFMPP) and, to a lesser extent, 1-benzyl-4-methylpiperazine (MBZP) are the most common piperazines family that appeared in the early market of NPS at the beginning of the 2000s and was sold as a "legal high" [1,2]. Piperazine moiety is a unique structure of diverse pharmacological importance 
with serious psychoactive properties because of the dopaminergic, noradrenergic and predominantly serotoninergic effects that produced in the brain by piperazines [1]. Of them, $\mathrm{mCPP}$ as a legal high is the most widespread piperazine with a safer reputation in some regions of the world than the best known one; BZP [3].

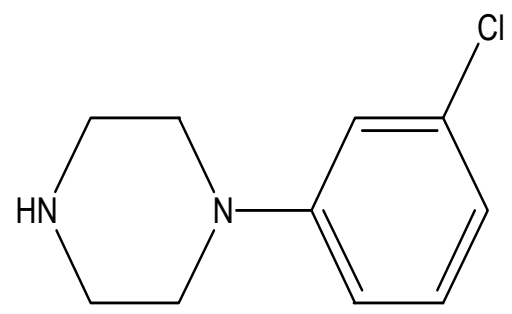

Figure 1. 1-(3-chlorophenyl)piperazine (mCPP).

As a matter of fact, $\mathrm{mCPP}$ is a 1-arylpiperazine derivative relatively inexpensive with legal availability that can be purchased from the chemical suppliers. Nevertheless, mCPP has been introduced by the organized crime through what is called the darknet open market either in its own right, which is rare, or even as a mixture of piperazines and mainly with a variable complex profile of pharmacologically active substances that pose problematic risk patterns among people who take these seized products with a special focus is given to the dose-dependent manner [4] and life-threatening serotonin syndrome of mCPP [5]. It is sold in mislabeled packages as tablets of distinctive appearance with variable quantity of dosage units/seizures ranged from 10-200 mg, whereas capsules and powders are less common. Unfortunately, this is predominantly a youth phenomenon used increasingly for recreational purposes in party or dance situations $[4,5]$. What is more important, mCPP produces a stimulant with "feeling euphoria" and a hallucination similar to those sought from 3,4-methylenedioxymethamphetamine (MDMA, ecstasy) as well as the same subjective effects providing the basis for the recreational use of this legal high [6]. Whilst, BZP/TFMPP combination aggregates the stimulant effect of BZP with hallucinogen-like actions of TFMPP to mimic the molecular mechanism of MDMA, but with a lower potency for the same dose [7]. This explains why $\mathrm{mCPP}$ passed off the ecstasy market as an alternative for MDMA in most ecstasy tablets or as a supplement to the MDMA-containing tablets and sold as "legal ecstasy" in the NPS market with imitation to the point that visually distinguishing mCPP-containing tablets from regular MDMA is impossible [8-10].

Apart from the black drug market, $\mathrm{mCPP}$ as one of the phenylpiperazine derivatives that are well-characterized serotonergic agents, the reason for the use of $\mathrm{mCPP}$ as a challenge probe for the serotonin function in psychiatric research with a dose up to about $50 \mathrm{mg}$ for a $70 \mathrm{~kg}$ person [5,11]. Interestingly, however, mCPP referred to as failed pharmaceutics and has never been authorized for medicinal purposes, it is the pharmacologically active metabolite that may be contribute to the therapeutic effects of the mentioned antidepressants; trazodone, nefazodone and etoperidone, and of the minor tranquilizer mepiprazole [4].

Taking into consideration these issues, there is a problematic situation that is paying specialty close attention to develop a precise analytical method for the determination of $\mathrm{mCPP}$ in a selective fashion. It was demonstrated that, the literature published for the identification and quantification of $\mathrm{mCPP}$ in different matrices are not so numerous and rely mainly on the recommended United Nations Office on Drugs and Crime "UNODC" sophisticated chromatographic methods; liquid chromatography-tandem mass spectrometry (LC-MS/MS) [12,13], high performance liquid chromatography with diode array detection (HPLC-DAD) [14] and gas chromatography coupled to mass spectrometry (GC-MS) [15,16] are the most prominent. As well, electrophoresis has been reported [17]. Although highly specific and sensitive all these techniques are very expensive, laborious with time consuming processes, require expertise technician and consume harmful organic solvents. 
Nevertheless, from the perspective of analytical chemistry, fast, precise, sensitive and nondestructive electrochemical sensors have rapidly gained momentum as a growing avenue of research. Importantly, they preclude the requirement of sample pretreatment providing eco-friendly and economic aspects. In addition, availability of portable, miniaturization, automation and affordable instruments with higher performance characteristics together with reasonable limits of detection and acceptable selectivity successfully cope with the demands for the determination of illicit substances in the black drug market. Notwithstanding the wide applications of electrochemical sensors for the determination of illicit substances [18-22], little has been reported about the determination of new psychoactive substances [22-24]. Moreover, it is of importance to mention that no chemical sensors have been performed yet for the determination of mCPP.

Potentiometric sensors are one of the utmost important groups of electrochemical sensors that have evolved to being well established as a robust analytical technique in many fields. However, potentiometric sensors based on ion-associates with lipophilic counter ions as a sensing element immobilized in a PVC matrix sometimes suffer from the limited selectivity as it is driven by a non-discriminatory ion-exchange mechanism with the fact that ion exchangers respond better to the more lipophilic cations. Therefore, interest was triggered to the vital importance of supramolecular chemistry and peculiarities of remarkable approach molecular recognition. In fact, synthetic materials with molecular recognition sites are paramount in many areas; one of them is the development of chemical sensors and in particular potentiometric ones to address more sensitive and selective sensors $[25,26]$.

In continuation of the earlier work on the design of sensors for the determination of illicit drugs $[27,28]$, and in light of the foregoing, it was motivated to synthesize a supramolecular architecture; [ $\mathrm{Na}\left(15\right.$-crown-5)][ $\left.\mathrm{BPh}_{4}\right]$ from the assembly of 15 -crown-5; 1,4,7,10,13-pentaoxacyclopentadecane and $\mathrm{NaBPh}_{4}$; sodium tetraphenylboron, to be investigated for the first time as a sensing element doped in a liquid contact polymeric membrane based selective sensors providing a sensitive and selective binding of mCPP. Furthermore, the emphasis has been placed on the comparison with the natural receptor $\beta$-cyclodextrin as an alternative sensing or recognizing element in the designed sensors for $\mathrm{mCPP}$.

\section{Experimental}

\subsection{Reagents and Materials}

All chemicals used were of analytical reagent grade, unless otherwise specified and doubly distilled water was used throughout. 15-crown-5; 1,4,7,10,13-pentaoxacyclopentadecane (CE, $\left.\mathrm{C}_{10} \mathrm{H}_{20} \mathrm{O}_{5}\right)$, sodium tetraphenylboron $\left(\mathrm{NaBPh}_{4}, \mathrm{NaTPB}\right)$, o-nitrophenyloctyl ether (o-NPOE), potassium tetrakis(p-chlorophenyl)borate $(\mathrm{KTpClPB})$ and dibutylsebacate (DBS) were obtained from Sigma Chemical Co., St. Louis, MO, USA. Tetrahydrofuran (THF) and dioctylphthalate (DOP) were purchased from British Drug Houses, Poole, England. High molecular weight polyvinyl chloride (PVC) and $\beta$-cyclodextrin ( $\beta$-CycD) were obtained from Aldrich Chemical Co. Milwaukee, WI, USA. 1-(3-chlorophenyl)piperazine (mCPP) hydrochloride was procured from Alfa Aesar, United Kingdom. A stock solution of mCPP hydrochloride $\left(5.0 \times 10^{-2} \mathrm{M}\right)$ was prepared by dissolving the calculated weight of pure $\mathrm{mCPP}$ hydrochloride in $50 \mathrm{~mL}$ of $5.0 \times 10^{-2} \mathrm{M}$ Tris- $\mathrm{HCl}$ buffer solutions at $\mathrm{pH} 7.0 \pm 0.05$ or in doubly distilled water and dilute solutions $\left(1.0 \times 10^{-7}-1.0 \times 10^{-2} \mathrm{M}\right)$ were prepared by successive dilutions of the stock solution. Solutions of interferences $\left(1.0 \times 10^{-2} \mathrm{M}\right)$ were prepared in a similar way for the study of potentiometric selectivity. All of the working solutions were buffered at $\mathrm{pH} 7.0 \pm 0.05$ using $5.0 \times 10^{-2} \mathrm{M}$ Tris- $\mathrm{HCl}$ buffer solutions.

\subsection{Apparatus}

Potentiometric measurements were performed at $25 \pm 1{ }^{\circ} \mathrm{C}$ using an ORION model Star 4 digital $\mathrm{pH} / \mathrm{mV}$ meter and $\mathrm{mCPP}$ membrane sensors in conjunction with an Orion double-junction $\mathrm{Ag} / \mathrm{AgCl}$ reference electrode $(90-02)$ containing $10 \%(\mathrm{w} / \mathrm{v})$ potassium nitrate in the outer compartment. An Orion 
Ross $\mathrm{pH}$ electrode (Model 81-02) was used for $\mathrm{pH}$ adjustment. The cell assembly was: $\mathrm{Ag} / \mathrm{AgCl} / 10^{-2} \mathrm{M}$ $\mathrm{KCl}-10^{-2} \mathrm{M} \mathrm{mCPP}$ hydrochloride/sensor membrane/sample test solution/Orion double junction reference electrode.

\subsection{Synthesis and Characterization of Sensing Elements}

2.3.1. 15-Crown-5•Sodium Tetraphenylboron; [ $\mathrm{Na}(15-$ crown-5) $]\left[\mathrm{BPh}_{4}\right]$ Supramolecular Architecture; $(\mathrm{CE} \bullet \mathrm{NaTPB})$

It was synthesized by using the procedure described [29], $220 \mathrm{mg}$ of 15 -crown-5 (1 mmole) dissolved in $10 \mathrm{ml}$ ethanol is added with stirring to $10 \mathrm{ml}$ of equimolar ethanolic solution of sodium tetraphenylboron ( $342 \mathrm{mg}, 1 \mathrm{mmole}$ ), a white crystalline complex is formed immediately through a sufficiently strong ion-dipole interaction upon the addition of the 15-crown-5. It was isolated by suction filtration, washed with ethanol and then dried for subsequent identification, Scheme 1 . It was demonstrated that the complex of 15 -crown- 5 with sodium tetraphenylboron has been shown to be 1:1 stoichiometry of 15-crown-5:NaTPB as confirmed by the founded $\%$ elemental analysis data; C; 72.8 and H; 7.07 that is in an agreement with the calculated \% values $C ; 72.5$ and $H ; 7.2$. This is a reasonable ratio that is often attributed to how well the sodium cation fits into the cavity of the crown ether demonstrating an optimum matching in size between the cavity of the 15-crown-5 and the sodium ion. The assignment of the structure was also confirmed with Fourier transform infrared spectral "FTIR" that seems reasonable bands concern the carbon ether oxygen stretching frequencies $v(\mathrm{C}-\mathrm{O}-\mathrm{C})$; a very strong band at $1081 \mathrm{~cm}^{-1}$ and strong one at $1117 \mathrm{~cm}^{-1}$ instead of $1128 \mathrm{~cm}^{-1}$ for uncomplexed 15-crown-5. In addition, the TPB frequencies observed at 741 and $711 \mathrm{~cm}^{-1}$ for NaTPB shifted to 737 and $705 \mathrm{~cm}^{-1}$, respectively in this supramolecular architecture indicating that the bulky anion had no effect.
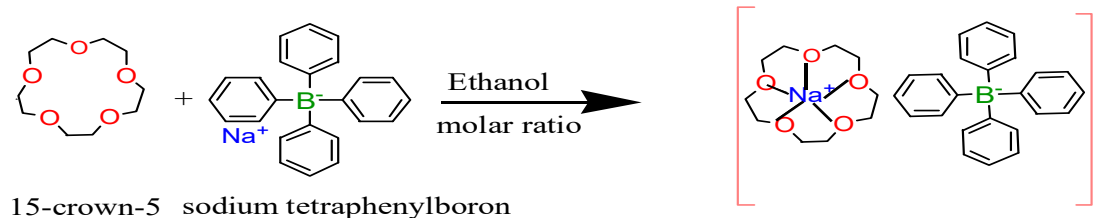

$$
\begin{gathered}
{\left[\mathrm{Na}\left(15 \text {-crown-5)][} \mathrm{BPh}_{4}\right]\right.} \\
\text { supramolecular architecture } \\
\text { (ionophore; } \mathbf{R})
\end{gathered}
$$

Scheme 1. For the synthesis of supramolecular architecture; [ $\mathrm{Na}\left(15\right.$-crown-5)][⿰ $\left.\mathrm{BPh}_{4}\right]$ "ionophore".

\subsubsection{Sodium Tetraphenylboron:m-Chlorophenylpiperazine $[\mathrm{mCPP}]^{+}:[\mathrm{TPB}]^{-}$Ion Pair}

The ion-pair associate was prepared by adding $10 \mathrm{ml}$ aqueous solution of $10^{-2} \mathrm{M} \mathrm{NaTPB}$ to $10 \mathrm{ml}$ of $10^{-2} \mathrm{M}$ mCPP hydrochloride aqueous solution. The resulting ion-pair associated precipitate was filtered, washed thoroughly with distilled water and dried at room temperature then grinded to a fine powder. The predicted composition of the ion associate complex had a molar ratio of $[\mathrm{mCPP}]^{+}:[\mathrm{TPB}]^{-}$ and was confirmed by an elemental analysis that calculated \%: $\mathrm{C} ; 78.9, \mathrm{H} ; 6.6$ and $\mathrm{N} ; 5.4$ and found $\%: \mathrm{C} ; 78.1, \mathrm{H} ; 6.6$ and $\mathrm{N} ; 5.6$. The calculated and experimental elemental analysis data for the ion-pair associate complex are in good agreement with its structure.

\subsection{Membrane and Sensor Preparation}

The polymeric membrane was prepared by dissolving $4 \mathrm{mg}$ of the ionophore; a sensing element with the lipophilic salt additive potassium tetrakis(p-chlorophenyl)borate (KTpClPB) as $50 \mathrm{wt} \%$ of the ionophore, $124 \mathrm{mg}$ of the plasticizer and $67 \mathrm{mg}$ of PVC in THF $3 \mathrm{~mL}$. The membrane cocktail was poured into a flat Petri dish $(28 \mathrm{~mm}$ i.d). Gradual evaporation of the THF at ambient temperature afforded an elastic, transparent membrane with a thickness of about $0.1 \mathrm{~mm}$. A dummy membrane refers to the same membrane cocktail described above, however, omitting the presence of a sensing element. Disks ( $\sim 4 \mathrm{~mm}$ o.d.) were punched from the master membrane and glued with a PVC/THF 
slurry to plasticized PVC tubing fixed onto a $1000 \mathrm{~mL}$ pipette tip. The tube was then filled with equal volumes of $1.0 \times 10^{-2} \mathrm{M} \mathrm{mCPP}$ hydrochloride and $1.0 \times 10^{-2} \mathrm{M} \mathrm{KCl}$ (internal solution) and an $\mathrm{Ag} / \mathrm{AgCl}$ wire ( 1 $\mathrm{mm}$ diameter) was immersed in this solution as an internal reference electrode. Before calibration, all fresh sensors were conditioning by soaking in a $1.0 \times 10^{-2} \mathrm{M} \mathrm{mCPP}$ hydrochloride solution for $2 \mathrm{~h}$ to activate the sensing element in the membrane before use. During the intervals between the individual measurements the sensors kept dry after rinsing with distilled water.

\subsection{EMF Measurement and Sensors Calibration}

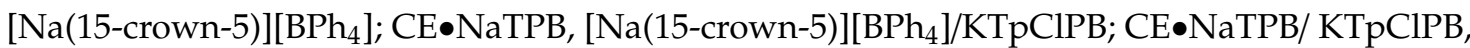
$[\mathrm{mCPP}]^{+}:[\mathrm{TPB}]^{-}$and $\beta-\mathrm{CycD} / \mathrm{KTpClPB}$ membrane based sensors were calibrated by immersion with an $\mathrm{Ag} / \mathrm{AgCl}$ double junction reference electrode into a $50 \mathrm{~mL}$ beaker containing $9 \mathrm{~mL}$ of $5.0 \times 10^{-2} \mathrm{M}$ Tris-HCl buffer solutions at $\mathrm{pH} 7.0$ portions $(0.2-1.0 \mathrm{~mL})$ of $1.0 \times 10^{-6}-5.0 \times 10^{-2} \mathrm{M}$ of standard $\mathrm{mCPP}$ hydrochloride solutions were successively spiked and the potential response of the constant stirred solutions was measured after stabilization to $\pm 0.2 \mathrm{mV}$. A calibration plot was constructed by plotting the EMF readings against the logarithm of $\mathrm{mCPP}$ concentrations.

\section{Results and Discussion}

\subsection{Performance Characteristics of m-Chlorophenylpiperazine Sensors}

\subsubsection{Membrane Response and Sensitivity of the Sensors}

Indded, simulation of natural phenomenon through molecular recognition; a process that plays a crucial role in the nature for the occurrence of life through prevailing reversible non-covalent interactions with high specificity and affinity seem to provide a sound basis for the design of ion selective sensors. Concurrently, the fascination of the self-assembly of small synthetic molecular building blocks through various non-covalent interactions has been applied to generate functional sophisticated supramolecular architectures with properties that cannot be deduced by a simple summation of the properties of the individual components. Moreover, they are capable again to engage targets through numerous and spatially distributed multiple binding interaction sites arising from the architecture as a whole providing high efficiency and selectivity [30,31]. Accordingly, the molecular recognition event is becoming also a fundamental process for efficient electrochemical sensors that may be implemented by the formation of a sensing element with the ability of multiple binding sites to assess binding strength of high affinity in a selective and a fast reversible manner followed by a transduction mechanism into a measurable signal for the attainment of highly selective sensors [32].

Arousing from the aforementioned points, it has been interested in designing a supramolecular architecture that must have feature binding sites to explore a potential sensing element "ionophore" for mCPP. Interestingly, the most important, and almost unique, feature of the crown ethers is their binding strengths and selective capture of alkali and alkaline earth metals. This resulted in the formation of many complexes of alkali metal salts with a range of counter anions; one of them is the weakly

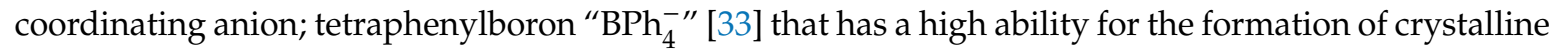
supramolecular complexes [34]. Therefore, the interaction with multidentate donor 15-crown-5 that is normally able to specifically accommodate the sodium ion, yielded a stable crystalline supramolecular

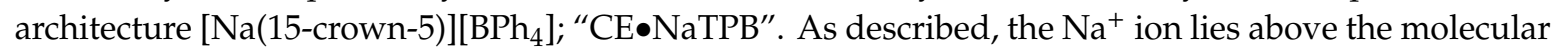
plane of 15 -crown- 5 and is coordinated to six oxygen atoms forming pentagonal pyramid coordination geometry. Five oxygen atoms from crown ether construct the base of the pentagonal pyramid and the sixth oxygen atom from another one is located at the vertex of pentagonal pyramid as well as hydrogen bonding interaction between the neighboring 15 -crown- 5 molecules and $\mathrm{BPh}_{4}^{-}$anion has been formed. Furthemore, the supramolecular hydrogen bonding chains are held together via van der Waals force to extend into the three-dimensional molecular crystal [29]. 
As a consequence, the potentiometric response of this supramolecular architecture (CE•NaTPB ) towards $[\mathrm{mCPP}]+$ is recognized in a realistic fashion through its stimulation as a sensing probe with an adequate plasticizer entrapped in a PVC polymeric membrane as long as an ion selective sensor has been designed. As anticipated, at first sight, a phase boundary potential; the main parameter governing the potentiometric response of the polymeric membrane based ion selective sensors under zero current condition is assumed through a local thermodynamic equilibrium at the sample/membrane interface [35]. Therefore, inherent potentiometric signal generation has furnished evidence for this selective transduction mechanism that dominates a sub-Nernstian response of $54.4 \pm 0.67 \mathrm{mV} / \mathrm{decade}$ with $r^{2}=0.9982$ "without anionic additive" and provides an opportunity to construct a linear dynamic range with a lower limit of detection down to $7.5 \times 10^{-6} \mathrm{M} \mathrm{mCPP}$ as can be seen from Figure 2. It must be important to mention that a "Dummy" membrane based solely on PVC and plasticizer had no significant response towards mCPP. At this point, it is worth noting that, this mechanism confers that the recognition event was achieved with a high binding affinity of [ $\mathrm{Na}(15$-crown-5)][BPh 4 enough to form a strong complex with mCPP at micromolar concentrations; micromolar affinity. Finally, it is afforded a clear evidence for the implementation of [ $\mathrm{Na}(15-\mathrm{crown}-5)]\left[\mathrm{BPh}_{4}\right]$ as an ionophore in selective sensors for the determination of mCPP.

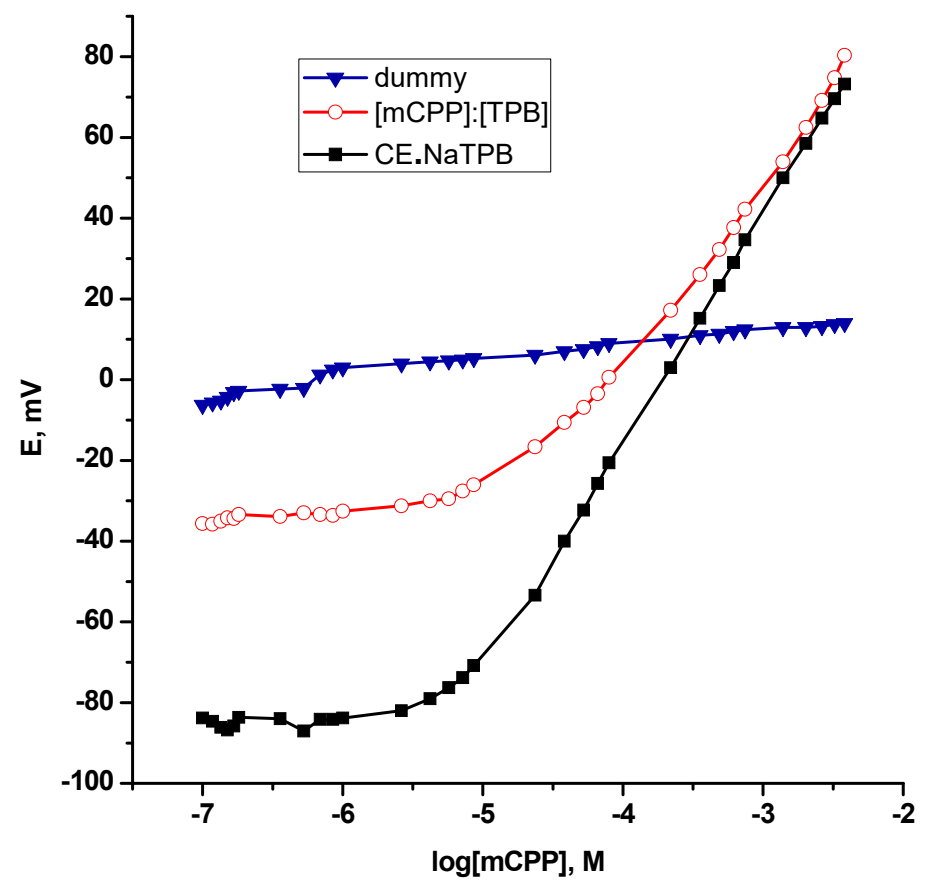

Figure 2. Calibration plots of ion exchanger and ionophore polymeric membrane based selective sensors for mCPP.

On other hand, it well demonstrated that low overall charge and high degree of charge delocalization with shielded negative charge over the entire anion so that no individual atom or group of atoms bears a high concentration of charge are the characteristics features of weakly coordinating anions [36]. Consequently, tetraphenylboron as an illustrative example can preclude strong ion pairing formation [37], which is an essential prerequisite for an ion exchanger based ion selective sensors [38]. Addtionally, the hindered steric accessibility of the $[\mathrm{mCPP}]^{+}$where the positive charge is located in the ring of $[\mathrm{mCPP}]^{+}$plays also a crucial role in an ion pair complexation. Accordingly, one can explain the performance characteristics of the $[\mathrm{mCPP}]^{+}:[\mathrm{TPB}]^{-}$ion pair as a sensing element that was much too weak to exhibit a potentiometric function, when it was cast integrally in a PVC matrix plasticized with DOP. A drastic reduction of the slope; $46.96 \pm 2.93 \mathrm{mV} /$ decade, a short linear range of about one decade; $2.2 \times 10^{-4}-2.6 \times 10^{-3} \mathrm{M}$ and most importantly a higher limit of detection; $4.0 \times 10^{-5} \mathrm{M}$ were 
assessed as can be seen from Table 1 and Figure 2. Generally it demonstrated a worse reproducibility of the response.

Table 1. Potentiometric performance characteristics of m-chlorophenylpiperazine polymeric membrane based selective sensors.

\begin{tabular}{|c|c|c|c|}
\hline Parameter & $\mathrm{CE} \bullet \mathrm{NaTPB} / \mathrm{KT}$ pCIPB & $\beta-\mathrm{CycD/KTpCIPB}$ & mCPP:TPB \\
\hline Slope, $\mathrm{mV} /$ decade $^{*}$ & $58.9 \pm 0.43$ & $55.2 \pm 0.60$ & $46.96 \pm 2.93$ \\
\hline Correlation coefficient $\left(\mathrm{r}^{2}\right)$ & 0.9998 & 0.9997 & 0.9985 \\
\hline Linear range, $\mathrm{M}$ & $1.0 \times 10^{-6}-1.0 \times 10^{-2}$ & $2.4 \times 10^{-5}-1.0 \times 10^{-2}$ & $2.2 \times 10^{-4}-2.6 \times 10^{-3}$ \\
\hline Detection limit, $\mathrm{M}$ & $5.0 \times 10^{-7}$ & $9.0 \times 10^{-6}$ & $4.0 \times 10^{-5}$ \\
\hline Working range $(\mathrm{pH})$ & $4-8$ & $4-8$ & $4-8$ \\
\hline Response time $(\mathrm{s}) \geq 10^{-4} \mathrm{M}$ & 5.0 & 15 & 50 \\
\hline Life span (week) & 8.0 & 5.0 & 1.0 \\
\hline Precision $\mathrm{CV}_{\mathrm{W}}(\%)$ & 1.10 & 1.14 & 6.23 \\
\hline Between-day variability $\mathrm{CV}_{\mathrm{b}}(\%)$ & 0.53 & 0.70 & 1.66 \\
\hline
\end{tabular}

* Average of ten measurements.

The distinction of (CE•NaTPB ) based sensors is sought to be due to the synergistic supramolecular

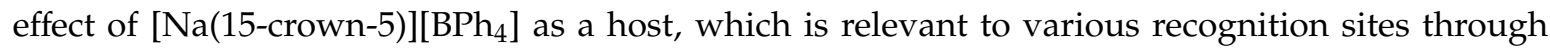
the possibility of non-covalent interactions, which are most prominent with the privileged scaffolds; arylpiperazine as the guest [39]. It must be important to mention that $\mathrm{mCPP}$ is a merger between the aryl group and piperazine group, where the piperazine core as a heterocyclic nitrogen compound has distinct structural flexibility with a six membered ring containing two nitrogen atoms at opposite positions, resulting in even molecular ions that has the availability of versatile binding properties particularly hydrogen bonding [40], as well as the protonated piperazine plays also a crucial role. Consequently, it is reasonable to postulate that aromatic-aromatic interactions ( $\pi$... $\pi$ stacking), hydrogen bonding $-\pi$ interactions; $(\mathrm{N}-\mathrm{H} \ldots \pi)$ and methylene hydrogen of piperazine $(\mathrm{C}-\mathrm{H} \ldots \pi)$ as well as cation $-\pi$ interactions $\left({ }^{+} \mathrm{N}-\mathrm{H} \ldots \pi\right)$ are the most available binding sites between $[\mathrm{mCPP}]^{+}$ and the delocalized $\pi$-system of tetraphenylboron moiety in the host "ionophore". Attention also must be paid to the role of the electron-withdrawing substituent chlorine atom in the aromatic moiety of $\mathrm{mCPP}$ that was resulted in a stronger affinity towards the ionophore. Moreover, the possibility of hydrophobic interactions can be operative and decisive also. Quite interestingly, these interactions were in line with the binding mechanism predicted by molecular docking for the interaction of $[\mathrm{mCPP}]^{+}$ with serotonin receptor subtypes "5- $\mathrm{HT}_{1 \mathrm{~A}}$ receptor", a major target for research and drug development due to its implication in many physiological processes [41] as well as with the adrenergic receptor; $\alpha_{1 \mathrm{~A}}$-adrenoceptor [42]. Furthermore, the piperazine core acts as a hydrogen bonding donating site with crown ether-oxygen atoms through $\mathrm{N}-\mathrm{H} \ldots \mathrm{O}$ and " $\mathrm{C}-\mathrm{H} \ldots \mathrm{O}$ ".

Taking into account a success in the ability of cyclodextrins CycDs to be effective to accommodate in a selective fashion various organic compounds in their central cavities that fulfill the structural requirements of the $\mathrm{CycD}$ cavity as a hydrophobic binding site and thereby numerous reports have been dedicated to highly selective sensors based CycDs [43]. Accordingly, it is important to gain insight into the comparison with the cited ionophore, in this context, native $\beta$-cyclodextrin was chosen as a naturally receptor; ionophore is embedded into a PVC polymeric membrane with an anionic additive; $\mathrm{p}-\mathrm{ClTPB}$ and $o$-NPOE as a plasticizer for the development $\beta-\mathrm{CycD} / \mathrm{KTpClPB}$ polymeric membrane based sensor for $\mathrm{mCPP}$. The sensor exhibited a sub-Nernstian value with a relative shorter linear range and a higher limit of detection Table 1 and Figure 3, probably, due to $\beta$-cyclodextrin interacting much weaker with piperazine as it can be accommodated by a benzene ring only in its cavity [44] and this is in agreement with the notion that the achievable sensitivity is limited by the affinity, which is the dominant contributor to the recognition mechanism. 


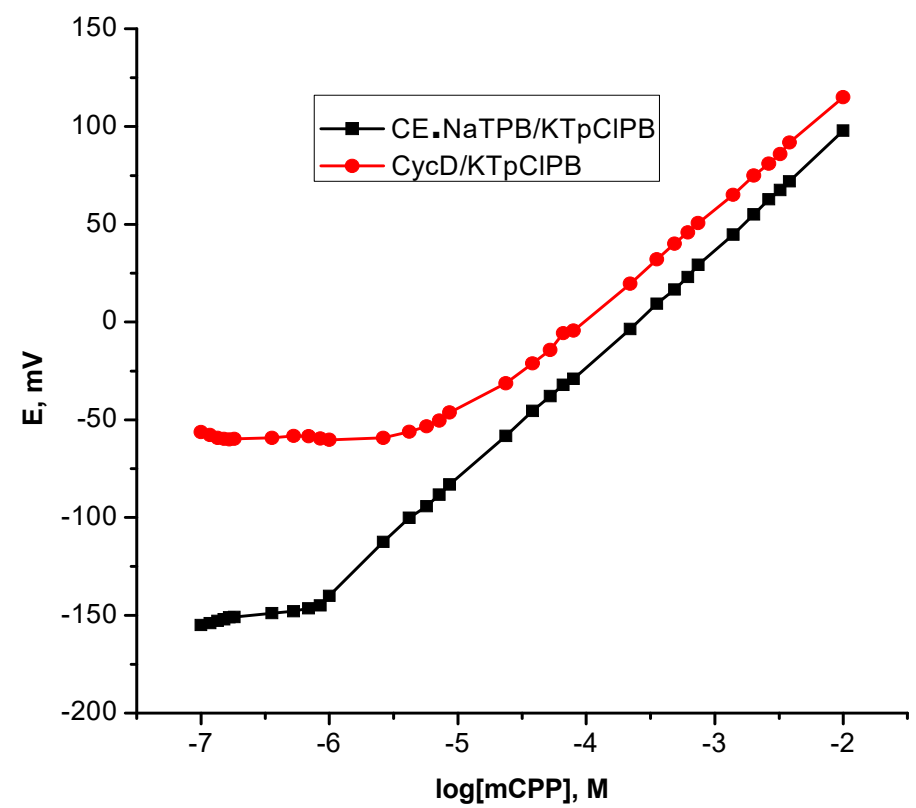

Figure 3. Calibration plots for m-chlorophenylpiperazine polymeric membrane based sensors.

\subsubsection{Optimization of the Membrane Composition}

Recognizing the role of the other membrane components; lipophilic anionic additives have been essential to optimize the proper performance of ionophore based sensors for allowing possibilities of practical applications of the sensors. Indeed, the crucial role of the anionic additive that ensures no significant amount of counter anions can be co-extracted into the membranes (Donnan exclusion) providing the permselectivity of the membrane as well as it reduces the electrical resistance of the membranes that allowing greater ion mobility within the membrane. Moreover, the addition of anionic additives lowers the activation barrier for the cation-exchange at the membrane-solution interface, which improves the interfacial ion-exchange kinetics $[45,46]$. Much more importantly, it constitutes a functional factor in dictating the lower limit of detection of ion selective sensors [47]. Accordingly, the quantitative treatment of $\mathrm{CE} \bullet \mathrm{NaTPB}$ ionophore based polymeric membrane sensors with incorporation of anionic additive; potassium tetrakis(p-chlorophenyl)borate (KTpClPB) resulted

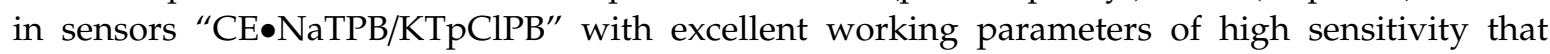
the response slope was closer to the ideal Nernstian value and a wider linear range as well as the anionic additive led to dramatic improvement in the lower limit of detection to be $5.0 \times 10^{-7} \mathrm{M}$, as can be seen from Table 1 and Figure 3 .

Importantly, light should be shed on the great impact of the plasticizer as a constitutive part of the membrane. Given the fact that different plasticizers were found to induce significantly different effects on the analytical performance of the ion selective sensors particularly for recognition mechanism based ion selective sensors, it was interesting to study the dependence of a dynamic linear range and the lower limit of detection on plasticizers, namely, DOP, DBS and o-NPOE, drawing attention to the Nernstian behavior of the sensors. As can be seen from Table 2 and Figure 4, a fact that was surprising at first sight, non-polar plasticizer DOP gave the best results, however, $o$-NPOE afforded the much poorer one that perhaps because most of the recognition binding process herein were electrostatic in nature that might be weakened with a high dielectric constant [48]. This is in excellent agreement with the notion that the plasticizer not only guarantees the physical properties of the membrane and provides both solubility of the ionophore and mobility of constituents within the membrane but also the stabilization/complexation of target ions within the membrane is a determining function of the plasticizer [45]. Therefore, DOP was chosen to be the optimum plasticizer for further studies. 
Table 2. Effect of plasticizers on the performance of m-chlorophenylpiperazine polymeric membrane based sensors.

\begin{tabular}{cccc}
\hline Plasticizer/Dielectric Constant, $\mathcal{\varepsilon}$ & Slope, $\mathbf{m V}$ /decade & Linear Range, $\mathbf{M}$ & Detection Limit, $\mathbf{M}$ \\
\hline DOP, 5.10 & 55.1 & $2.4 \times 10^{-5}-3.9 \times 10^{-3}$ & $7.5 \times 10^{-6}$ \\
DBS, 4.46 & 55.6 & $3.8 \times 10^{-5}-3.9 \times 10^{-3}$ & $3.0 \times 10^{-5}$ \\
NPOE, 24.0 & 61.8 & $2.2 \times 10^{-4}-3.9 \times 10^{-3}$ & $5.0 \times 10^{-5}$ \\
\hline
\end{tabular}

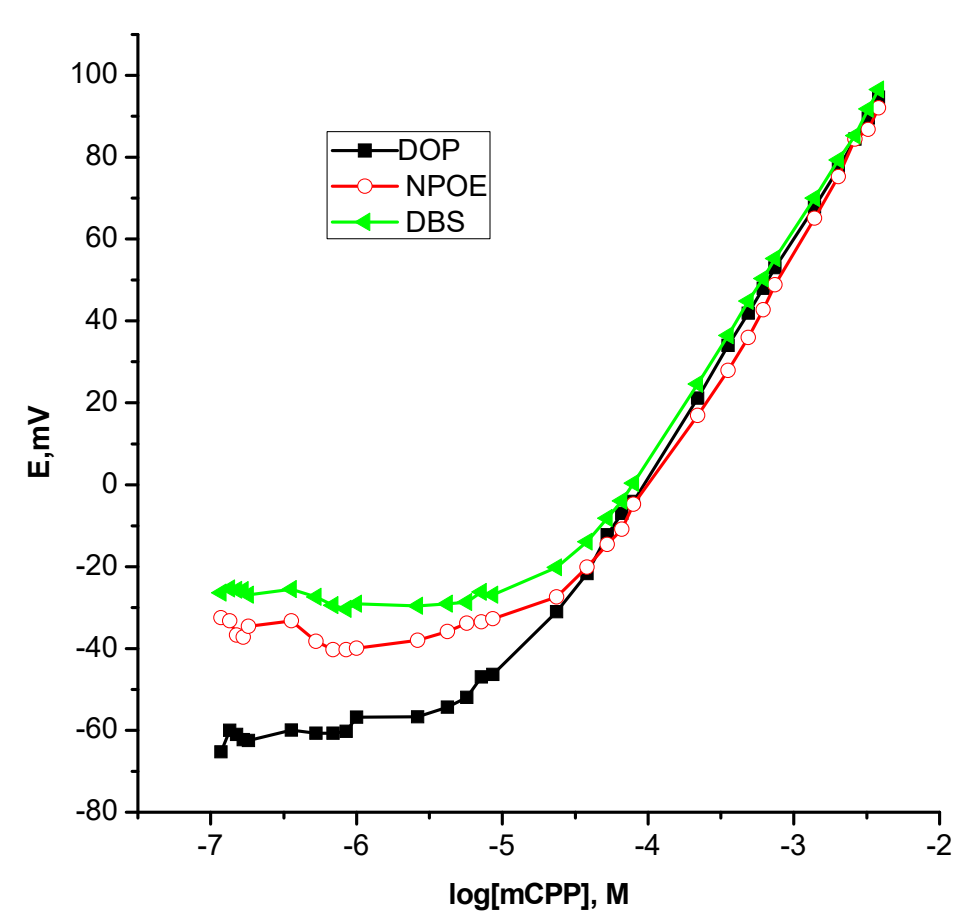

Figure 4. Effect of plasticizers on the performance of $\mathrm{m}$-chlorophenylpiperazine polymeric membrane based sensors.

\subsection{Response Time and $p H$ Effect}

Response time is of the utmost practical importance and defines the aspects of the rate-determining process of the analyte-membrane interaction. The average time required for the sensor to reach a steady potential response within $\pm 1 \mathrm{mV}$ of the final equilibrium value at the interface between liquid electrolytes and ion-conducting polymeric membrane after successive immersion of a series of mCPP solutions, each having a 10-fold difference in concentration was investigated. It is noteworthy to mention that the molecular recognition process attainment with a fast reversible exchange rate was $10 \mathrm{~s}$ for low concentrations of $1 \times 10^{-7}$ to $1 \times 10^{-5} \mathrm{M}$ and $5 \mathrm{~s}$ for high concentrations of $1 \times 10^{-4}$ to $1 \times 10^{-2} \mathrm{M}$ $\mathrm{mCPP}$ hydrochloride inherent with the $\mathrm{CE} \bullet \mathrm{NaTPB}$ ionophore. Meanwhile, the $\beta$-cyclodextrin based sensor exhibited $20 \mathrm{~s}$ and $15 \mathrm{~s}$ for low and high concentrations, respectively. Aside from specific binding sites affinity, the binding sites are to be complemented with a molecular periphery, which ensures sufficient lipophilicity of the ionophore and its compatibility with the sensor membrane matrix to fulfill the lifetime requirement of the sensors. In this study, the assembly of sodium tetraphenylboron with crown ether as well as adequate solubility in the proper plasticizer "DOP" provided the lifetime of the sensors to be extended to more than eight weeks without a significant change in the performance of the sensors (sensitivity, and linear range) was observed. Meanwhile, $\beta$-CycD exhibited a lifetime of five weeks. On the other hand, a dramatic deterioration with a very short lifetime of about one week probably attributed to the gradual leaching out of the ion exchanger from the membrane as well with another cited disadvantage that is the long response time that exceeds two min for the lower concentrations was encountered with the $[\mathrm{mCPP}]^{+}:[\mathrm{TPB}]^{-}$ion pair based sensor. 
The influence of $\mathrm{pH}$ on the potential of the sensors was investigated at concentrations $1.0 \times 10^{-4}$ and $1.0 \times 10^{-3} \mathrm{M}$ of $\mathrm{mCPP}$. The $\mathrm{pH}$ values of the sensors were adjusted by the addition of small volumes of dilute $\mathrm{HCl}$ or dilute $\mathrm{NaOH}$ solutions and the potential of the solution at each $\mathrm{pH}$ value was measured and plotted against the $\mathrm{pH}$. The results indicated that the sensors could function effectively in $\mathrm{pH}$ ranges $4-8$ for all sensors incorporating $\mathrm{CE} \bullet \mathrm{NaTPB}, \mathrm{CE} \bullet \mathrm{NaTPB} / \mathrm{KTpClPB}, \beta-\mathrm{CycD} / \mathrm{KTpClPB}$ receptors and $[\mathrm{mCPP}]^{+}:[\mathrm{TPB}]^{-}$ion pair, and this $\mathrm{pH}$ range was considered for further studies. The gradual decrease in the potential observed at a $\mathrm{pH}$ above 8 was due to the gradual decrease in the protonated forms of $\mathrm{mCPP}$ and formation of a free base. Evaluation of the main operating features for all sensors under constant $\mathrm{pH}$ was carried out in several buffer solutions prepared within the corresponding operational $\mathrm{pH}$ ranges. It was found that of the buffers investigated, $5.0 \times 10^{-2} \mathrm{M}$ Tris- $\mathrm{HCl}$ buffer at $\mathrm{pH} 7.0 \pm 0.05$ proved to be the optimal.

\subsection{Selectivity}

As stated in the introduction, street seized mCPP is a cocktail with morphine, codeine, ecstasy and amphetamine being the most prominent psychoactive substances as well as caffeine was the most common cutting agent $[5,17,49]$. Moreover, ephedrine and norephedrine must be taken into account as precursors for the synthesis of amphetamines. With such considerations in mind, the selectivity of the suspected method is a main concern and logic would seem to dictate the selectivity by the empirical matched potential method "MPM" [50] except otherwise stated and the results are summarized in Table 3. An important mention, particularly from the point of view of ion selective sensors, was that MPM got rid of the limitations of the corresponding methods based on the Nikolski-Eisenman equation for the determination of potentiometric selectivity coefficients, and expressed the extent of interference without any theoretical implication and reflected the real-world experimental behavior of the sensor as closely as possible. In MPM, the selectivity coefficient is defined as the activity ratio of the primary ion and the interfering ion that gives the same potential change in a reference solution according to Equation (1).

$$
\mathrm{k}_{\mathrm{mCPP}, \mathrm{j}}^{\mathrm{MPM}}=\frac{\Delta \mathrm{a}_{\mathrm{mCPP}}}{\mathrm{a}_{\mathrm{j}}}, \quad \text { with } \Delta \mathrm{a}_{\mathrm{mCPP}}=>\mathrm{a}_{\mathrm{mCPP}}-\mathrm{a}_{\mathrm{mCPP}}
$$

where: $\mathrm{a}_{\mathrm{mCP}}$ is a known activity (concentration) of mCPP added into a background solution containing a fixed activity and $\mathrm{a}_{\mathrm{mCPP}}\left(5.0 \times 10^{-5} \mathrm{M}\right) \mathrm{mCPP}$ in the presence of $5.0 \times 10^{-2} \mathrm{M}$ Tris-HCl buffer solutions at $\mathrm{pH} 7.0$ to generate a potential change of $\Delta \mathrm{EMF}=10.0 \mathrm{mV}$. Meanwhile, the concentration of each foreign ion (with a stock solution of $1.0 \times 10^{-2} \mathrm{M}$ ) was changed according to the MPM method. At the same time, the separate solution method "SSM" was also applied to evaluate the selectivity coefficients of amino acids and inorganic ions [51]. The concentrations of $\mathrm{mCPP}$ and the interferents were kept at a level of $1.0 \times 10^{-3} \mathrm{M}$ solutions of the same $\mathrm{pH} 7.0$ and the potentiometric selectivity coefficients were evaluated according to Equation (2), Table 4.

$$
\log K_{m C P P, j}^{p o t}=\frac{\mathrm{E}_{j}-\mathrm{E}_{m C P P}}{\mathrm{~S}}+\left(1-\frac{1}{\mathrm{z}_{I}}\right) \log 1 \times 10^{-3} \mathrm{M} \mathrm{mCPP},
$$

where $E_{j}$ and $E_{m C P P}$ are the sensor potentials for interfering ions $\mathrm{j}$ and $\mathrm{mCPP}$, respectively, $\mathrm{z}_{I}$ is the charge of interfering ions and $S$ is the slope of the calibration plot. 
Table 3. Potentiometric selectivity coefficients $\left(-\log k_{\mathrm{mCPP}, \mathrm{MPM}}^{\mathrm{MP}}\right)$ of m-chlorophenylpiperazine polymeric membrane based sensors (MPM).

\begin{tabular}{ccc}
\hline Interferent & CE॰NaTPB/KTpCIPB & $\beta-C y c D / K T p C 1 P B$ \\
\hline m-chlorophenylpiperazine & 0.0 & 0.0 \\
morphine & 2.91 & 1.60 \\
codeine & 2.37 & 0.72 \\
ephedrine & 2.02 & 0.90 \\
norephedrine & 2.62 & 1.65 \\
dextromethorphan & 2.16 & 0.42 \\
caffeine & 2.70 & 0.89 \\
\hline
\end{tabular}

Table 4. Potentiometric selectivity coefficients $\left(-\log K_{m C P P, j}^{p o t}\right)$ of $\mathrm{m}$-chlorophenylpiperazine polymeric membrane based sensors (SSM).

\begin{tabular}{|c|c|c|}
\hline Interferent & $\mathrm{CE} \bullet \mathrm{NaTPB} / \mathrm{KTpClPB}$ & $\beta-\mathrm{CycD/KTpCIPB}$ \\
\hline phenylalanine & 3.09 & 1.59 \\
\hline glycine & 3.07 & 1.72 \\
\hline $\mathrm{Na}^{+}$ & 3.19 & 1.78 \\
\hline $\mathrm{NH}_{4}^{+}$ & 3.57 & 2.06 \\
\hline $\mathrm{Ca}^{2+}$ & 3.40 & 1.89 \\
\hline $\mathrm{K}^{+}$ & 3.21 & 1.89 \\
\hline
\end{tabular}

Evidently, as can be seen from Tables 3 and 4, this ionophore displayed an excellent selective recognition toward $\mathrm{mCPP}$ to an extent that was a hundred times more than the psychoactive substances of major concern. This finding revealed that $\mathrm{CE} \bullet \mathrm{NaTPB}$ ionophore possesses sufficient multifunctional binding centers in a geometrically matching position with mCPP [52]. On account of the stronger binding of the ionophore to a target ion is, the more selectivity will be dictated, a low selectivity associated with $\beta$-cyclodextrin based sensor was displayed.

\subsection{Analytical Applications}

As a result, the lower detection limits observed was much more than enough to permit analysis of real life samples in the illicit market with adequate selectivity, however, it was hard to find illicit samples. Therefore, to demonstrate the practical utility of the sensors; 10,35 and $100 \mathrm{mg}$ of $\mathrm{mCPP}$ hydrochloride, which concur with the functional concentration range of the sensors were taken as pure samples and this process was repeated three times $(n=3)$, Table 5 .

Table 5. Determination of $\mathrm{mCPP}$ in pure samples using $\mathrm{CE} \bullet \mathrm{NaTPB} / \mathrm{KTpClPB}$ polymeric membrane based sensors.

\begin{tabular}{ccc}
\hline Weighted, $\mathbf{m g}$ & Found, $\mathbf{m g} \pm$ SD & Recovery, $\%$ \\
\hline 10.0 & $10.25 \pm 0.05$ & 102.5 \\
35.0 & $34.83 \pm 0.40$ & 99.5 \\
100.0 & $100.3 \pm 0.14$ & 100.3 \\
\hline
\end{tabular}

\subsection{Method Validation}

Stringent requirements concerning the linearity (correlation coefficient; $\mathrm{r}^{2}$ ), sensitivity (slope), precision $(\mathrm{CVw})$, between-day variability $(\mathrm{CVb})$, lower limit of detection and accuracy (recovery) for the reliability of analytical methods was demonstrated. For the sensors incorporating $\mathrm{CE} \bullet \mathrm{NaTPB} / \mathrm{KTpClPB}$, the linear responses were obtained within the $\mathrm{mCPP}$ concentrations range from $10^{-6}$ to $10^{-2} \mathrm{M}$ with a slope closer to the ideal Nernstian value of $58.9 \pm 0.43 \mathrm{mV} /$ decade and a correlation coefficient, $\mathrm{r}^{2}=0.9998$, evidenced the good linearity of the calibration plot and the detection limit was 
$5.0 \times 10^{-7} \mathrm{M}$ as well as a good precision of $1.10 \%$. It is obvious that the fabricated sensors could be presented for determination of $\mathrm{mCPP}$ in pure solutions with good average recoveries $(99.5-102.5 \%)$. On the other hand, the $\beta$-cyclodextrin based sensors " $\beta$-CycD/KTpClPB" exhibited a sub-Nernstian behavior with $55.2 \pm 0.6 \mathrm{mV} /$ decade within the linear range of $2.4 \times 10^{-5}-1.0 \times 10^{-2} \mathrm{M}\left(\mathrm{r}^{2}=0.9997\right)$, a detection limit of $9.0 \times 10^{-6} \mathrm{M}$ and also a good precision of $1.14 \%$. The results revealed that the binding affinity of the ionophore plays a decisive role in the performance of ion selective sensors as stated previously.

\section{Conclusions}

Currently, the chemical analysis of illicit substances in the black drug market is gaining in great significance. Herein, the assembly of tetraphenylboron with crown ether fine-tuned its characteristics and led to a supramolecular architecture $[\mathrm{Na}(15-\mathrm{crown}-5)]\left[\mathrm{BPh}_{4}\right]$ with relevant multifunction binding sites, which in turn provided high affinity towards mCPP. Regarding this fact, the liquid contact polymeric membrane based sensors with $[\mathrm{Na}(15-\mathrm{crown}-5)]\left[\mathrm{BPh}_{4}\right]$ as an ionophore and anionic additive, KTpCIPB, plasticized with DOP provided excellent Nernstian behavior with a slope of $58.9 \pm 0.43 \mathrm{mV} /$ decade, a wide dynamic range from $10^{-6}$ to $10^{-2} \mathrm{M}$ and as low a detection limit as possible of $5.0 \times 10^{-7} \mathrm{M}$. It should be noted that the optimum characteristic performance of the suspected sensors met many of the necessary requirements for the determination of $\mathrm{mCPP}$ in the illicit market with a particularly attractive feature of high selectivity over other psychoactive substances in the real samples and a respond concentration range that $\mathrm{mCPP}$ could be quantified in the street samples (10-200 mg). On the other hand, sensors with the tetraphenylboron $[\mathrm{mCPP}]^{+}:[\mathrm{TPB}]^{-}$ion pair based sensor exhibited worse results; a slope of $46.96 \pm 2.93 \mathrm{mV} /$ decade, a short linear range of $2.2 \times 10^{-4}-2.6 \times 10^{-3} \mathrm{M}$ and most importantly a higher limit of detection of $4.0 \times 10^{-5} \mathrm{M}$ with fast deterioration of about one week lifetime. The comparison with native $\beta$-cyclodextrin as an ionophore showed that polymeric membrane sensors with $\left[\mathrm{Na}\left(15-\right.\right.$ crown$\left.\left.^{-5}\right)\right]\left[\mathrm{BPh}_{4}\right]$ were preferable. It is also interesting to mention that this method afforded reliable results for which a subsequent quantitative confirmation analysis was usually unnecessary and thereby has considerable practical use and probably market potential. It is of importance to note that this was the first designed sensor for selective determination of mCPP. Finally, the relationship of ion selective sensors methodology with supramolecular chemistry via the simulation of a natural phenomenon seems a promising feature for the determination of new psychoactive substances in the real world as a sensitive method with remarkable selectivity as well as an eco-friendly approach.

Conflicts of Interest: The author declare no conflicts of interest.

\section{References}

1. United Nations Office on Drugs and Crime (UNODC), the Challenge of New Psychoactive Substances, A Report from the Global SMART Programme March 2013. Available online: http://www.unodc.org/ documents/scientific/NPS_2013_SMART.PDF (accessed on 28 October 2018).

2. de Boer, D.; Bosman, I.J.; Hidvégi, E.; Manzoni, C.; Benko, A.A.; dos Reys, L.J.A.L.; Maes, R.A.A. Piperazine-like compounds: A new group of designer drugs-of-abuse on the european market. Forensic Sci. Int. 2001, 121, 47-56. [CrossRef]

3. European Monitoring Centre for Drugs and Drug Addiction (EMCDDA) 2009. BZP and Other Piperazines. Available online: http://www.emcdda.europa.eu/publications-/drug-profiles/bzp (accessed on 17 January 2019).

4. World Health Organization. 1-(3-chlorophenyl) Piperazine (mCPP) Pre-Review Report, Expert Committee on Drug Dependence. In Proceedings of the Thirty-fifth Meeting, Hammamet, Tunisia, 4-8 June 2012.

5. European Police Office, Europol-EMCDDA Joint Report on A New Psychoactive Substance: 1-(3-chlorophenyl) Piperazine (mCPP), European Monitoring Center on Drugs and Drug Addiction. 2005. Available online: http://www.emcdda.europa.eu/attachements.cfm/att_33256EN_Final_EuropolEMCDDA_ Active_Monitoring_Report_mCPP_290307.Pdf (accessed on 1 December 2018). 
6. Tancer, M.E.; Johanson, C.-E. The subjective effects of MDMA and mCPP in moderate MDMA users. Drug Alcohol Depend. 2001, 65, 97-101. [CrossRef]

7. Baumann, M.H.; Clark, R.D.; Budzynski, A.G.; Partilla, J.S.; Blough, B.E.; Rothman, R.B. N-substituted piperazines abused by humans mimic the molecular mechanism of 3,4-methylenedioxymethamphetamine (MDMA, or Ecstasy). Neuropsychopharmacology 2005, 30, 550-560. [CrossRef]

8. Brunt, T.M.; Nagy, C.; Bücheli, A.; Martins, D.; Ugarte, M.; Beduwe, C.; Vilamala, M.V. Drug testing in Europe: Monitoring results of the Trans European Drug Information (TEDI) project. Drug Test. Anal. 2017, 9, 188-198. [CrossRef]

9. Romão, W.; Lalli, P.M.; Franco, M.F.; Sanvido, G.; Schwab, N.V.; Lanaro, R.; Costa, J.L.; Sabino, B.D.; Bueno, M.I.M.S.; de Sa, G.F.; et al. Chemical profile of meta chlorophenylpiperazine (m-CPP) in ecstasy tablets by easy ambient sonic-spray ionization, X-ray fluorescence, ion mobility mass spectrometry and NMR. Anal. Bioanal. Chem. 2011, 400, 3053-3064. [CrossRef] [PubMed]

10. Bossong, M.G.; Brunt, T.M.; Van Dijk, J.P.; Rigter, S.M.; Hoek, J.; Goldschmidt, H.M.J.; Niesink, R.J.M. mCPP: An undesired addition to the ecstasy market. J. Psychopharmacol. 2010, 24, 1395-1401. [CrossRef]

11. Kahn, R.S.; Wetzler, S. m-Chlorophenylpiperazine as a probe of serotonin function. Biol. Psychiatry 1991, 30, 1139-1166. [CrossRef]

12. Patel, B.N.; Sharma, N.; Sanyal, M.; Shrivastav, P.S. High throughput and sensitive determination of trazodone and its primary metabolite, m-chlorophenylpiperazine, in human plasma by liquid chromatography-tandem mass spectrometry. J. Chromatogr. B 2008, 871, 44-54. [CrossRef]

13. Lendoiro, E.; Jiménez-Morigosa, C.; Cruz, A.; Páramo, M.; López-Rivadulla, M.; de Castro, A. An LC-MS/MS methodological approach to the analysis of hair for amphetamine-type stimulant (ATS) drugs, including selected synthetic cathinones and piperazines. Drug Test. Anal. 2017, 9, 96-105. [CrossRef]

14. Moreno, I.E.D.; da Fonseca, B.M.; Barroso, M.; Costa, S.; Queiroz, J.A.; Gallardo, E. Determination of piperazine-type stimulants in human urine by means of microextraction in packed sorbent and high performance liquid chromatography-diode array detection. J. Pharm. Biomed. Anal. 2012, 61, 93-99. [CrossRef]

15. Byrska, B.; Zuba, D.; Stanaszek, R. Determination of piperazine derivatives in "legal highs". Probl. Forensic Sci. 2010, 81, 101-113.

16. Kuleya, C.; Hall, S.; Gautam, L.; Cole, M.D. An optimized gas chromatographic-mass spectrometric method for the chemical characterization of benzylpiperazine and 1-arylpiperazine based drugs. Anal. Methods 2014, 6, 156-163. [CrossRef]

17. S Siroká, J.; Polesel, D.N.; Costa, J.L.; Lanaro, R.; Tavares, M.F.M.; Polášek, M. Separation and determination of chlorophenylpiperazine isomers in confiscated pills by capillary electrophoresis. J. Pharm. Biomed. Anal. 2013, 84, 140-147. [CrossRef]

18. Asturias-Arribas, L.; Alonso-Lomillo, M.A.; Domínguez-Renedo, O.; Arcos-Martínez, M.J. Sensitive and selective cocaine electrochemical detection using disposable sensors. Anal. Chim. Acta 2014, 834, 30-36. [CrossRef] [PubMed]

19. Tadini, M.C.; Balbino, M.A.; Eleoterio, I.C.; de Oliveira, L.S.; Dias, L.G.; Demets, G.J.-F.; de Oliveira, M.F. Developing electrodes chemically modified with cucurbit [6] uril to detect 3,4-methylenedioxymethamphetamine (MDMA) by voltammetry. Electrochim. Acta 2014, 121, 188-193. [CrossRef]

20. Balbino, M.A.; Oiye, É.N.; Ribeiro, M.F.M.; Júnior, J.W.C.; Eleotério, I.C.; Ipólito, A.J.; de Oliveira, M.F. Use of screen-printed electrodes for quantification of cocaine and $\Delta^{9}$-THC: Adaptions to portable systems for forensic purposes. J. Solid State Electrochem. 2016, 20, 2435-2443. [CrossRef]

21. Khairy, M.; Mahmoud, B.G.; Banks, C.E. Simultaneous determination of codeine and its co-formulated drugs acetaminophen and caffeine by utilizing cerium oxide nanoparticles modified screen-printed electrodes. Sens. Actuators B Chem. 2018, 259, 142-154. [CrossRef]

22. Shaw, L.; Dennany, L. Applications of electrochemical sensors: Forensic drug analysis. Curr. Opin. Electrochem. 2017, 3, 23-28. [CrossRef]

23. Smith, J.P.; Metters, J.P.; Khreit, O.I.G.; Sutcliffe, O.B.; Banks, C.E. Forensic electrochemistry applied to the sensing of new psychoactive substances: Electroanalytical sensing of synthetic cathinones and analytical validation in the quantification of seized street samples. Anal. Chem. 2014, 86, 9985-9992. [CrossRef]

24. Razavipanah, I.; Alipour, E.; Deiminiat, B.; Rounaghi, G.H. A novel electrochemical imprinted sensor for ultrasensitive detection of the new psychoactive substance "Mephedrone". Biosens. Bioelectron. 2018, 119, 163-169. [CrossRef] 
25. Ganjali, M.R.; Norouzi, P.; Rezapour, M.; Faridbod, F.; Pourjavid, M.R. Supramolecular based membrane sensors. Sensors 2006, 6, 1018-1086. [CrossRef]

26. Búhlmann, P.; Pretsch, E.; Bakker, E. Carrier-based ion-selective electrodes and bulk optodes. 2. ionophores for potentiometric and optical sensors. Chem. Rev. 1998, 98, 1593-1687. [CrossRef] [PubMed]

27. El-Naby, E.H. Selective ketamine recognition based on membrane potential changes induced by a hybrid organic/inorganic supramolecular assembly. Anal. Methods 2014, 6, 900-906. [CrossRef]

28. El-Naby, E.H.; Kamel, A.H. Potential transducers based man-tailored biomimetic sensors for selective recognition of dextromethorphan as an antitussive drug. Mater. Sci. Eng. C 2015, 54, 217-224. [CrossRef] [PubMed]

29. Yuan, G.-J.; Liu, S.-X.; Tian, Z.-F.; Ren, X.-M. A high temperature reversible phase transition in a supramolecular complex of 15-crown-5 with tetraphenylboron sodium. New J. Chem. 2018, 42, 14943-14948. [CrossRef]

30. Lehn, J.-M. Toward self-organization and complex matter. Science 2002, 295, 2400-2403. [CrossRef]

31. Zarra, S.; Wood, D.M.; Roberts, D.A.; Nitschke, J.R. Molecular containers in complex chemical systems. Chem. Soc. Rev. 2015, 44, 419-432. [CrossRef]

32. Lavigne, J.J.; Anslyn, E.V. Sensing a paradigm shift in the field of molecular recognition: From selective to differential Receptors. Angew. Chem. Int. Ed. 2001, 40, 3118-3130. [CrossRef]

33. Parsons, D.G.; Truter, M.R.; Wingfield, J.N. Alkali metal tetraphenyl-borate complexes with some macrocyclic, "crown", polyethers. Inorg. Chim. Acta 1975, 14, 45-48. [CrossRef]

34. Kiviniemi, S.; Nissinen, M.; Alaviuhkola, T.; Rissanen, K.; Pursiainen, J. The complexation of tetraphenylboron with organic N-heteroaromaticcations. J. Chem. Soc. Perkin Trans. 2001, 2, 2364-2369. [CrossRef]

35. Bakker, E.; Bühlmann, P.; Pretsch, E. The phase-boundary potential model. Talanta 2004, 63, 3-20. [CrossRef] [PubMed]

36. Strauss, S.H. The search for larger and more weakly coordinating anions. Chem. Rev. 1993, 93, 927-942. [CrossRef]

37. Andreeva, N.A.; Chaban, V.V. Understanding weakly coordinating anions: Tetrakis (pentafluorophenyl) borate paired with inorganic and organic cations. J. Mol. Model. 2017, 23, 86-94. [CrossRef] [PubMed]

38. Kharitonov, S.V. Membrane drotaverine-selective electrodes based on tetraphenyl-borate derivatives: Electrochemical, adsorption, and transport properties and analytical application. J. Anal. Chem. 2006, 61, 902-911. [CrossRef]

39. Horton, D.A.; Bourne, G.T.; Smythe, M.L. The combinatorial synthesis of bicyclic privileged structures or privileged substructures. Chem. Rev. 2003, 103, 897-930. [CrossRef] [PubMed]

40. Wang, L.; Zhao, L.; Xu, L.; Chen, R.; Yang, Y. Interesting organic supramolecular structures constructed by piperazine/ $\mathrm{N}, \mathrm{N}^{\prime}$-dimethylpiperazine with aromatic multicomponent acids: Synthon cooperation and structural diversity. CrystEngComm 2012, 14, 6998-7008. [CrossRef]

41. Zlatović, M.V.; Šukalović, V.V.; Schneider, C.; Roglić, G.M. Interaction of arylpiperazine ligands with the hydrophobic part of the 5-HT $\mathrm{HA}_{1 \mathrm{~A}}$ receptor binding site. Bioorg. Med. Chem. 2006, 14, 2994-3001. [CrossRef]

42. Zhao, X.F.; Wang, J.; Liu, G.X.; Fan, T.P.; Zhang, Y.J.; Yu, J.; Wang, S.X.; Li, Z.J.; Zhang, Y.Y.; Zheng, X.H. Binding mechanism of nine $\mathrm{N}$-phenylpiperazine derivatives and $\alpha 1 \mathrm{~A}$-adrenoceptor using site directed molecular docking and high performance affinity chromatography. RSC Adv. 2015, 5, 57050-57057. [CrossRef]

43. Lenik, J.; Nieszporek, J. Construction of a glassy carbon ibuprofen electrode modified with multi-walled carbon nanotubes and cyclodextrins. Sens. Actuators B Chem. 2018, 255, 2282-2289. [CrossRef]

44. Zhang, Y.-M.; Yang, Z.-X.; Chen, Y.; Ding, F.; Liu, Y. Molecular binding and assembly behavior of $\beta$-cyclodextrin with piperazine and 1,4-dioxane in aqueous solution and solid state. Cryst. Growth 2012, 12, 1370-1377. [CrossRef]

45. Bakker, E.; Bühlmann, P.; Pretsch, E. Carrier-Based Ion-Selective Electrodes and Bulk Optodes. 1. General Characteristics. Chem. Rev. 1997, 97, 3083-3132. [CrossRef] [PubMed]

46. Gehrig, P.; Morf, W.E.; Welti, M.; Pretsch, E.; Simon, W. Catalysis of Ion Transfer by tetraphenylborons in Neutral Carrier-Based Ion-Selective Electrodes. Helv. Chem. Acta 1990, 73, 203-212. [CrossRef]

47. Petrukhin, O.M.; Kharitonov, A.B.; Frakiisky, E.V.; Urusov, Y.I.; Zhukov, A.F.; Shipway, A.N.; Baulin, V.E. The effect of lipophilic anionic additives on detection limits of ion-selective electrodes based on ionophores with phosphoryl complexing groups. Sens. Actuators B Chem. 2001, 76, 653-659. [CrossRef]

48. Janata, J. Principles of Chemical Sensors, 2nd ed.; Springer: Dordrecht, The Netherlands; Heidelberg, Germany; London, UK; New York, NY, USA, 2009; pp. 14-17. 
49. United Nations Office on Drugs and Crime (UNODC). International Quality Assurance Programme (IQAP); International Collaborative Exercises (ICE) Summary Report Seized Materials; The Laboratory and Scientific Section UNODC, International Centre: Vienna, Austria, 2014.

50. Tohda, K.; Dragoe, D.; Shibata, M.; Umezawa, Y. Studies on the matched potential method for determining the selectivity coefficients of ion-selective electrodes based on neutral ionophores: Experimental and theoretical verification. Anal. Sci. 2001, 17, 733-743. [CrossRef] [PubMed]

51. Umezawa, Y.; Búhlmann, P.; Umezawa, K.; Tohda, K.; Amemiya, S. Potentiometric selectivity coefficients of ion-selective electrodes part I. inorganic cations. Pure Appl. Chem. 2000, 72, 1851-2082. [CrossRef]

52. Schneider, H.-J.; Yatsimirsky, A.K. Selectivity of chemical receptors. In Artificial Receptors for Chemical Sensors, 1st ed.; Mirsky, V.M., Yatsimirsky, A.K., Eds.; WILEY-VCH Verlag GmbH \& Co. KGaA: Weinheim, Germany, 2011; pp. 17-65.

C 2019 by the author. Licensee MDPI, Basel, Switzerland. This article is an open access article distributed under the terms and conditions of the Creative Commons Attribution (CC BY) license (http://creativecommons.org/licenses/by/4.0/). 